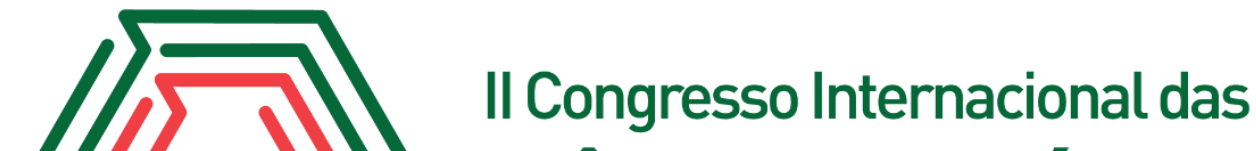 Ciências Agrárias COINTER - PDVAgro 2017
}

\section{DESENVOLVIMENTO RADICULAR DA SOJA EM CAMADAS SUBSUPERFICIAIS DO SOLO SOB APLICAÇÃO DE HIDRÓXIDO DE CÁLCIO}

\author{
Apresentação: Pôster
}

\begin{abstract}
Weslei dos Santos Cunha ${ }^{1}$; Luciano Nascimento de Almeida ${ }^{2}$; Mônica Silva de Oliveira ${ }^{3}$; Tadeu Cavalcante Reis ${ }^{4}$;
\end{abstract}

\section{Introdução}

A acidez dos solos é reconhecidamente uma das principais limitações para o desenvolvimento das culturas. Em solos ácidos diversos nutrientes têm sua absorção dificultada pela presença de altos teores tóxicos de alumínio. As raízes da maior parte das plantas não se desenvolvem bem em solos ácidos por duas razões principais: Excesso de alumínio ou deficiência de cálcio. É bastante comum esses dois fatores ocorrerem associados, principalmente em solos de baixa fertilidade natural como a região do cerrado (MALAVOLTA, 1985).

Dessa maneira a correção da acidez do solo tem efeitos benéficos que influenciam no desempenho das culturas, favorecendo a nitrificação da matéria orgânica, que possui efeito positivo na fixação simbiótica do nitrogênio, além de beneficiar as propriedades físicas pela adição de cátions floculantes aos colóides do solo, que consequentemente estimula sistemas radiculares mais extensos, uma vez que ocorrerá o aproveitamento de água e nutrientes de forma mais eficiente.

Geralmente são utilizados corretivos como calcário e gesso para buscar neutralizar a acidez dos solos, no entanto o calcário encontra uma limitação por não ter capacidade de atingir camadas profundas do solo, e o gesso por não possuir capacidade de neutralizar os efeitos causados pelo alumínio. Nesse contexto, corretivos como a cal hidratada, que apresenta alta solubilidade e capacidade de percolação em camadas profundas, podem atuar como novas alternativas para potencializar o cultivo de culturas em solos que apresentam acidez subsuperficial. O objetivo desse

\footnotetext{
${ }^{1}$ Engenharia agronômica, Universidade do Estado da Bahia, wsc.agronomo@gmail.com

2 Engenharia agronômica, Universidade do Estado da Bahia Inalmeida.engagro@gmail.com

3 Engenharia agronômica, Universidade do Estado da Bahia, monica.so@live.com

${ }^{4}$ Doutor, Universidade do Estado da Bahia, tadeu@uneb.br
} 
trabalho foi avaliar os efeitos da aplicação da cal hidratada [Ca $(\mathrm{OH}) 2]$ sobre o desempenho do sistema radicular da cultura da soja.

\section{Fundamentação Teórica}

Geralmente, no cultivo de culturas anuais, há uma preocupação em corrigir a camada arável do solo, ou seja, até os $20 \mathrm{~cm}$ de profundidade. No entanto, em períodos de estiagem, a camada superficial é insuficiente para fornecer o volume de água necessária para o desenvolvimento das culturas. Nesse contexto, o enraizamento profundo pode contribuir para o melhor aproveitamento de água e nutrientes. Todavia, em camadas mais profundas do solo, normalmente, a acidez atua como uma barreira ao desenvolvimento das raízes (RAIJ, 2011).

\section{Metodologia}

O experimento foi conduzido em casa de vegetação, na Universidade do Estado da Bahia UNEB, Campus IX, localizada nas seguintes localizações geográficas: $12^{\circ} 08^{\prime} 655^{\prime}$ 'S e 4457'827" W, no município de Barreiras, no Oeste da Bahia. O clima, é do tipo Aw, com temperatura média anual de $24^{\circ} \mathrm{C}$ e precipitação média anual próxima a $1110 \mathrm{~mm}$, distribuídas nos meses de novembro a março.

Utilizou-se um Latossolo vermelho amarelo distrófico típico, classificado pela SiBCS, este foi coletado no bioma do cerrado, de forma estratificada, em uma propriedade no município de São Desidério, no Oeste da Bahia. O solo foi coletado em cinco profundidades de (0-20; 20-40; 40-60; 60-80; 80-100 cm), em seguida as amostras foram encaminhadas para análise em laboratório, onde foi caracterizado como solo ácido, típico do cerrado, apresentando $\mathrm{pH}$ 5,0. Os solos coletados foram realocados em canos de PVC, com $15 \mathrm{~cm}$ de diâmetro e $100 \mathrm{~cm}$ de altura, na mesma ordem de profundidade da coleta. O delineamento experimental empregado foi o inteiramente casualizado, composto por um fatorial $2 \times 5$, sendo as parcelas divididas em duas formas de aplicação (diluída e incorporada) e cinco doses crescentes $(0 ; 2,5 ; 5,0 ; 7,5$ e 10 t/ha) de cal hidratada $[\mathrm{Ca}(\mathrm{OH}) 2]$ equivalente a PRNT $100 \%$.

Após a aplicação das doses de cal hidratada e umedecimento dos tratamentos até a capacidade de campo, as parcelas permaneceram em casa de vegetação, recebendo reposição de água, em função da perda de massa, por um período de 30 dias, tempo necessário para que o material reaja no solo. Logo em seguida, semeou-se a variedade de soja M8349 IPRO, com plantas apresentando alta estabilidade e ampla adaptabilidade. Aos 80 dias, no final do ciclo da cultura 
foram analisadas as massas fresca e seca do sistema radicular, sendo quantificada em cada camada de solo remontada.

Os dados foram submetidos a análise de variância e posteriormente os tratamentos qualitativos foram analisados por meio do teste de Tukey, utilizando o software estatístico Assistat, versão 7.7. A análise de regressão foi aplicada aos tratamentos quantitativos, considerando-se coeficientes de determinação maiores ou iguais a $70 \%$.

\section{Resultados e Discussões}

A aplicação incorporada de $\mathrm{Ca}(\mathrm{OH}) 2$ promoveu maior massa fresca no sistema radicular da soja em todas as camadas subsuperficiais do solo. Foi apenas na camada superficial que a aplicação diluída proporcionou os maiores valores nessa variável (Tabela 1). Tal resultado pode ser explicado pelo fato de que, na aplicação incorporada, o revolvimento do solo favoreceu a descida do corretivo até as camadas mais profundas do solo, melhorando, dessa forma, as condições químicas necessárias ao desenvolvimento do sistema radicular da planta. No caso da forma diluída de aplicação, o não revolvimento do solo pode ter impedido que o $\mathrm{Ca}(\mathrm{OH}) 2$ descesse à subsuperfície em decorrência de uma possível barreira física formada pela compactação. Com os componentes de correção do solo bloqueados na superfície, o sistema radicular tende a se concentrar na mesma (BRAIT, 2016).

Tabela 1. Massa fresca do sistema radicular da soja nas cinco camadas do solo em função das formas de aplicação do hidróxido de cálcio. Fonte: Própria

\begin{tabular}{lccccc}
\hline Formas de & \multicolumn{5}{c}{ Massa fresca da raiz $(\mathbf{g})$} \\
\cline { 2 - 6 } $\begin{array}{c}\text { aplicação de } \\
\text { Ca(OH) }\end{array}$ & $\begin{array}{c}\mathbf{0 - 2 0} \\
\text { cm }\end{array}$ & $\begin{array}{c}\mathbf{2 0 - 4 0} \\
\text { cm }\end{array}$ & $\begin{array}{c}\mathbf{4 0 - 6 0} \\
\text { cm }\end{array}$ & $\begin{array}{c}\mathbf{6 0 - 8 0} \\
\mathbf{c m}\end{array}$ & $\begin{array}{c}\mathbf{8 0 - 1 0 0} \\
\mathbf{c m}\end{array}$ \\
\hline Diluída & $1,36 \mathrm{a}$ & $0,28 \mathrm{~b}$ & $0,18 \mathrm{~b}$ & $0,09 \mathrm{~b}$ & $0,09 \mathrm{~b}$ \\
\hline Incorporada & $1,09 \mathrm{~b}$ & $0,33 \mathrm{a}$ & $0,23 \mathrm{a}$ & $0,12 \mathrm{a}$ & $0,20 \mathrm{a}$ \\
\hline CV $(\%)$ & 4,37 & 8,55 & 11,39 & 14,14 & 46,07 \\
\hline
\end{tabular}

Médias seguidas de mesmas letras minúsculas nas colunas não diferem entre sí.

No acúmulo de matéria seca do sistema radicular, já não houve diferença entre as formas de aplicação de $\mathrm{Ca}(\mathrm{OH}) 2$ nas camadas entre 40 e $80 \mathrm{~cm}$. Nas demais camadas analisadas, as formas de aplicação apresentaram o mesmo comportamento obtido na variável anterior (Tabela 2). O aumento no teor de cálcio do solo, em razão da correção deste, induz ao acúmulo de massa seca nas raízes (PRADO \& NATALE, 2004). 
Tabela 2. Massa seca do sistema radicular da soja nas cinco camadas do solo em função das formas de aplicação do hidróxido de cálcio. Fonte: própria

\begin{tabular}{lccccc}
\hline $\begin{array}{c}\text { Formas de } \\
\text { aplicação de } \\
\text { Ca(OH) }\end{array}$ & $\begin{array}{c}\mathbf{0 - 2 0} \\
\mathbf{c m}\end{array}$ & $\begin{array}{c}\mathbf{2 0 - 4 0} \\
\mathbf{c m}\end{array}$ & $\begin{array}{c}\mathbf{4 0 - 6 0} \\
\mathbf{c m}\end{array}$ & $\begin{array}{c}\mathbf{6 0 - 8 0} \\
\mathbf{c m}\end{array}$ & $\begin{array}{c}\mathbf{8 0 - 1 0 0} \\
\mathbf{c m}\end{array}$ \\
\hline Diluída & $1,16 \mathrm{a}$ & $0,23 \mathrm{~b}$ & $0,23 \mathrm{a}$ & $0,09 \mathrm{a}$ & $0,07 \mathrm{~b}$ \\
\hline Incorporada & $0,93 \mathrm{~b}$ & $0,25 \mathrm{a}$ & $0,17 \mathrm{a}$ & $0,08 \mathrm{a}$ & $0,11 \mathrm{a}$ \\
\hline $\mathrm{CV}(\%)$ & 6,8 & 11,21 & 72,73 & 68,58 & 19,39 \\
\hline
\end{tabular}

Médias seguidas de mesmas letras minúsculas nas colunas não diferem entre sí.

Nas camadas 20-40 e 60-80 cm, a aplicação diluída das doses de $\mathrm{Ca}(\mathrm{OH}) 2$ proporcionou um ajuste quadrático nos valores de massa fresca das raízes, havendo um aumento nestes a partir da dose 2,9 e 3,6 tha-1 nas respectivas camadas. Com a incorporação das doses, a massa fresca do sistema radicular apresentou comportamento quadrático nas camadas 0-20, 60-80 e 80-100 cm (Figura 1). Tanto nas doses diluídas quanto nas incorporadas, não houve ajuste de modelo de regressão na camada 40-60 cm para os dados de massa fresca.

Figura 1. Massa fresca do sistema radicular nas camadas do solo em função de doses diluídas (A) e incorporadas (B) de hidróxido de cálcio $[\mathrm{Ca}(\mathrm{OH}) 2]$. Fonte: Própria

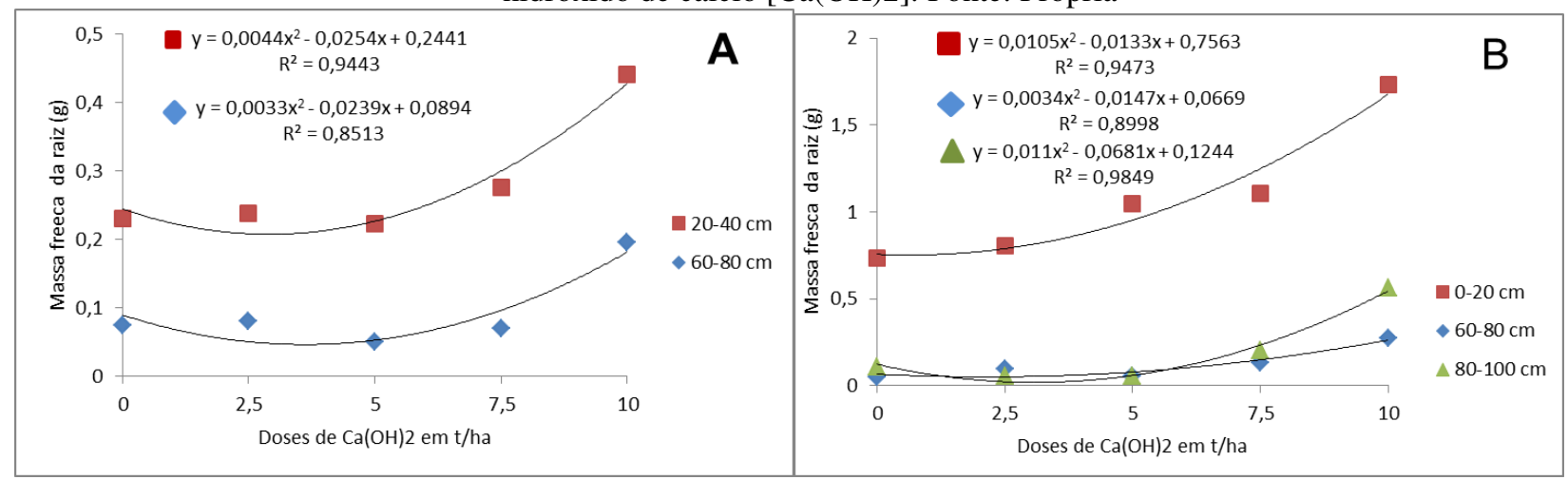

$\mathrm{Na}$ variável massa seca do sistema radicular, apenas a camada $20-40 \mathrm{~cm}$ apresentou regressão significativa com a diluição das doses. Os valores sofreram leve decréscimo até atingir a dose 2,6 t ha-1 e aumentaram consideravelmente a partir de então. Nas doses incorporadas, a matéria seca apresentou comportamento semelhante à massa fresca em todas as camadas (Figura 2). 
Figura 2. Massa seca do sistema radicular nas camadas do solo em função de doses diluídas (A) e incorporadas (B) de hidróxido de cálcio $\left[\mathrm{Ca}(\mathrm{OH})_{2}\right]$. Fonte: Própria

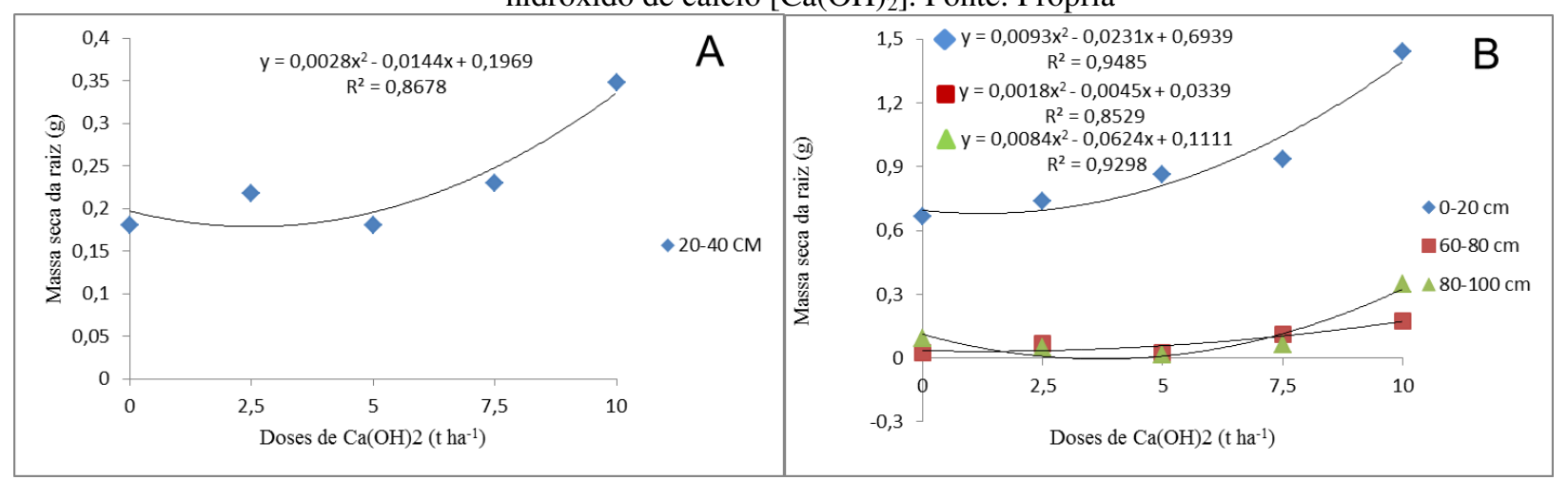

\section{Conclusões}

A aplicação incorporada de $\mathrm{Ca}(\mathrm{OH}) 2$ favorece o crescimento do sistema radicular da soja em camadas subsuperficiais do solo.

O aumento nas doses de $\mathrm{Ca}(\mathrm{OH}) 2$ incorporadas permite a elevação da massa radicular até um metro de profundidade.

\section{Referências}

BRAIT, M. H. Perfil do solo. Disponível em: <http://www.labexata.com.br/blog/exibir.asp?id=27\&post=perfil- do-solo>. Acesso em 15 out. 2017.

MALAVOLTA, E. Nutrição mineral. In: FERRI, M, G., ed. Fisiologia vegetal 1. ed. São Paulo: EPU, 1985. p. 97-116.

PRADO, R. M.; NATALE, W. Calagem na nutrição de cálcio e no desenvolvimento do sistema radicular da goiabeira.

RAIJ, B. V. Melhorando o ambiente radicular em subsuperfície. Informações agronômicas. n. 135, 2011. 